\title{
A novel gate driving scheme for high power PWM and bypass switches
}

\author{
Dong-Myung Lee ${ }^{1 \mathrm{a})}$, Thomas L. Keister ${ }^{2}$, Jae-Hyeong $\mathrm{Seo}^{3}$, \\ Thomas G. Habetler ${ }^{4}$, Ronald G. Harley ${ }^{4}$, \\ and Joseph R. Rostron ${ }^{5}$ \\ ${ }^{1}$ School of Electronic and Electrical Engineering, Hongik University \\ 72 Sangsu-Dong, Mapo-Gu, Seoul 121-791, Korea \\ 2 JSL, Inc. \\ 1860 Barnett Shoals Road STE 103-601, Athens, Georgia 30605, USA \\ ${ }^{3}$ MEMS Research and Innovation Center, Qualcomm MEMS Technology \\ 2581 Junction Avenue, San Jose, CA 95134, USA \\ ${ }^{4}$ School of Electrical and Computer Engineering, Georgia Institute of Technology \\ Atlantic Drive NW, Atlanta, Georgia 30332, USA \\ ${ }^{5}$ Southern States LLC \\ 30 Georgia Avenue, Hampton, Georgia 30228, USA \\ a)dmlee@hongik.ac.kr
}

Abstract: This paper proposes a new driving scheme for insulated gate bipolar junction transistors (IGBTs) and thyristors used for high power conversion. Most power conversion techniques are based on switching actions so that gate driving scheme and their related circuits have important roles in power conversion. In this paper, fault-tolerant gate driving schemes for power switches and their power supply that utilizes stored energy in the system are presented. Experiments have been carried out with $6500 \mathrm{~V}$-rated IGBTs and thyristors to verify the validity of the proposed driving scheme.

Keywords: gate driver, power supply, PWM

Classification: Electronic instrumentation and control

\section{References}

[1] S. Castagno, R. D. Curry, and E. Loree, "Analysis and comparison of a fast turn-on series IGBT stack and high-voltage-rated commercial IGBTs," IEEE Trans. Plasma Sci., vol. 34, no. 5, pp. 1692-1696, Oct 2006.

[2] P. R. Palmer and H. S. Rajamani, "Active voltage control of IGBTs for high power application," IEEE Trans. Power Electron. vol. 19, no. 4, pp. 894-901, July 2004.

[3] T. Jalakas, D. Vinnikov, and J. Laugis, "Development of 50-kW isolated DC/DC converter with high voltage IGBTs," Compatibility in Power Electron., pp. 1-6, May 2007.

[4] S. Park and T. M. Jahns, "A self-boost charge pump topology for a gated drive high-side power supply," Conf. Rec. IEEE APEC, pp. 126-131, 2003. 
[5] B. K. Bose, Power Electronics and AC drives, Prentice-Hall, New Jersey, 1986.

\section{Introduction}

With the remarkable progress in the technology of high power rating devices, various power conversion methods and devices have been researched and developed. Most power conversion techniques are based on switching actions with variation of on-time of switches, i.e. pulse width modulation (PWM). For this purpose, an insulated gate bipolar junction transistor (IGBT) is the most suitable device due to its fast switching time, and low conduction loss etc. $[1,2]$. Besides high speed switching, low speed switching like power line frequency of $60 \mathrm{~Hz}$ can also be employed for controlling or bypassing input power. Usually, thyristors are the best candidate due to their high surge and continuous current capability.

The paper proposes gate driving schemes of IGBTs and thyristors, which are implemented in the equipment named voltage sag supporter that regulates output voltage by high speed switching of IGBTs, denoted as PWM switches, during voltage sag events and does bypassing the input power by thyristors, denoted as bypass switches, do with line frequency switching with natural commutation during normal operation condition.

For a power supply of gate drivers, isolated DC/DC converters are usually used. In the low-voltage application in order to reduce system cost, a bootstrap scheme is wildly used. However, these schemes have drawbacks such as necessity of high voltage transformer [3], and the significant limitation to meet the periodic charge time requirement for bootstrapping capacitors [4]. To avoid using a power supply based on DC/DC converters requiring highisolation voltage level, a new gate power supplying scheme that utilizes stored energy in the system with low voltage isolation level is proposed.

There has been much research activity in gate drive circuit of IGBTs and thyristors. Much research focuses on performance improvement of IGBTs. The system in this paper operated with both PWM and bypass switches, and in normal voltage conditions, the input power are delivered by bypass switches. Therefore, to have a reliable operation for bypass switches, this paper presents a new dual driving scheme having electrical and mechanical ways to activate bypass switches. Furthermore, the proposed gate driving scheme includes protection and status feedback scheme existed in commercialized driving boards.

\section{Gate drive operations of voltage sag supporter}

Fig. 1 (a) shows the voltage sag mitigation device operated by the proposed gate driving circuits. It has two kinds of switch block, a IGBT and a thyristor. The IGBT operates during a voltage sag condition and regulates the output voltage corresponding to a PWM duty-cycle. A thyristor is used as a bypass 
switch in an inverse parallel configuration, which connects the input power to the load unless the sag condition is present, i.e. bypassing the power. From experimental results shown in Fig. 1 (b) presenting the well regulated output voltage responding to the input voltage having a $40 \%$ sag, the validity of the proposed gate driving scheme can be verified. Fig. 1 (c) shows the gate driving signals corresponding to bypass mode, (a)-(b) and (c)-(d) periods and PWM mode, (b)-(c) period, during the voltage sag event. Fig. 1(d) shows measured gated signals for each device corresponding to the voltage drop event.
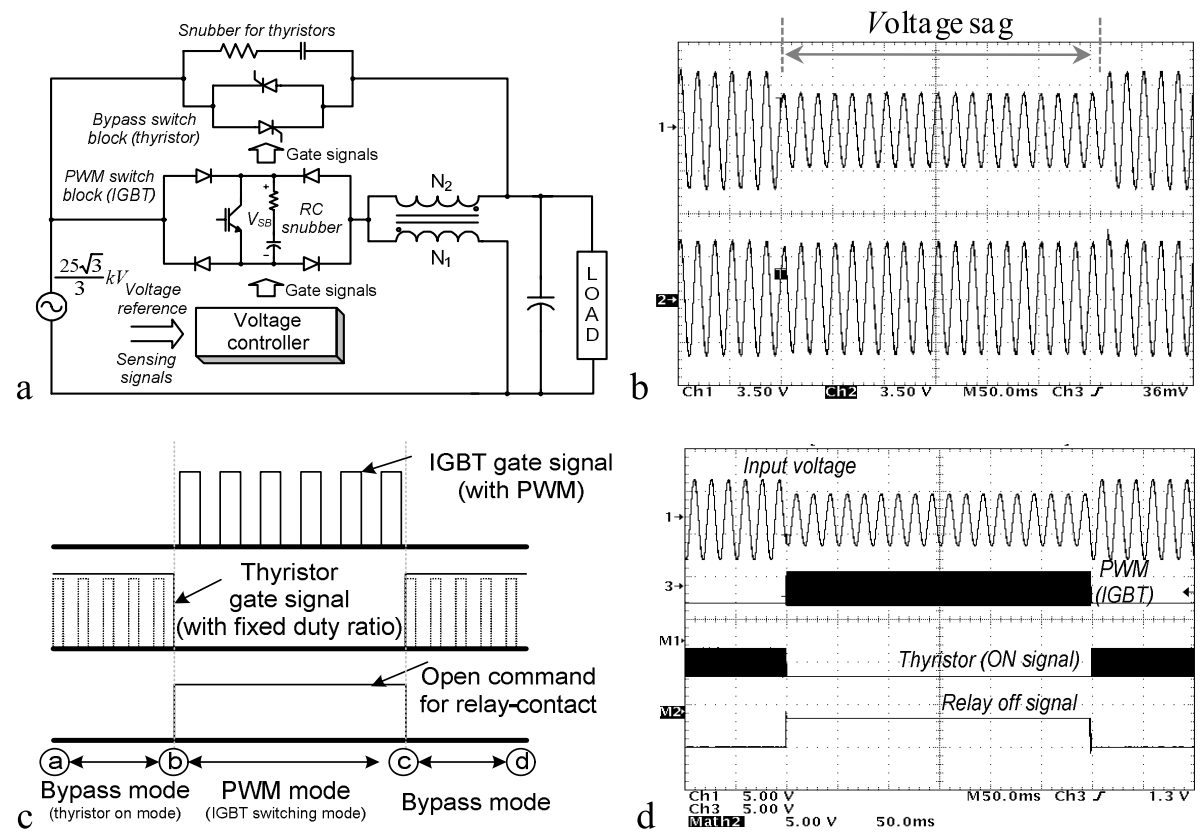

Fig. 1. (a) configuration of the voltage sag supporter consisting of PWM and bypass switches (b) measured input voltage having a $40 \%$ sag and resultant output voltage (c) gate signals corresponding to PWM and bypass mode (d) measured input voltage and gate signals

\section{Gate driver and gate power circuit for PWM switch, IGBT}

Fig. 2 (a) shows the IGBT switch block consisting of one $6500 \mathrm{~V} / 400 \mathrm{~A}$ IGBT, four $4500 \mathrm{~V}$ diodes, the gate driver, the power supply, and the RC snubber. It has a bridge configuration to allow current flow in both directions. To increase noise immunity a fiber optic cable is used for transferring gate signal and status feedback signals. Fig. 2 (b) shows schematic of the proposed power supply. Considering the reliable operation under abnormal voltage conditions such as voltage sag and the level of isolation, a new scheme for power supply has been proposed instead of employing conventional DC/DC power converters. It does not need a high voltage isolation transformer. Main building blocks of the power supply are a switching device and a linear regulator. 
Capacitors in the power supply, $C_{i n}$, are charged through the power resistor, $R_{\text {power }}$. The power for the gate driver is generated from the $\mathrm{RC}$ charging circuit located in parallel with the RC snubber. It utilizes the stored energy from the RC snubber that is always energized regardless of operation modes either PWM or bypass mode. The voltage across each RC snubber circuit, $V_{S B}$ shown in Fig. 1 (a) during the normal operation mode can be expressed as

$$
V_{S B}=\left(1-\frac{N_{1}}{N_{1}+N_{2}}\right) \times \frac{V_{i n}}{p} .
$$

Where, $N_{1}$ and $N_{2}$ are number of turns in the primary and secondary side of transformer, respectively. $V_{i n}$ is the peak value of the input voltage, and $p$ is total number of the serially connected IGBT blocks. Even Fig. 1 (a) shows one block of IGBT and thyristor, $p$ IGBT blocks are serially connected in actual implementation to withstand the input voltage level. The energy in RC snubber circuit of Fig. 2 (a) is transferred to $C_{i n}$ via the resistor $R_{\text {power }}$, and the $15 \mathrm{~V}$ level for IGBT gate driver is obtained by the linear regulator, $I C_{2}$. In the case that the voltage level of $C_{i n}$ is over the predetermined input voltage range, the switch $S W_{1}$ is turned on by the signal from the $I C_{1}$, a power supply voltage monitor. The diode $D_{B L}$ is required to hinder the discharge of the $C_{1}$ during $S W_{1}$ is on. Turn-on voltage level of $S W_{1}$ is determined by resistor values of $R_{1}$ and $R_{2}$.

Since the voltage across the RC snubber is a $\mathrm{DC}$ value, the diode bridge consisting of $D_{1} \sim D_{4}$ is not necessary, but to use this configuration for thyristor block as well, in which the input is $\mathrm{AC}$ value, the diode bridge

a

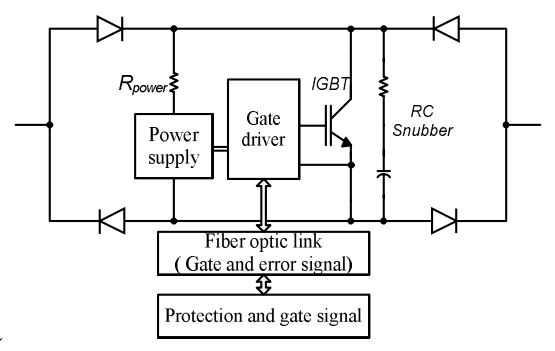

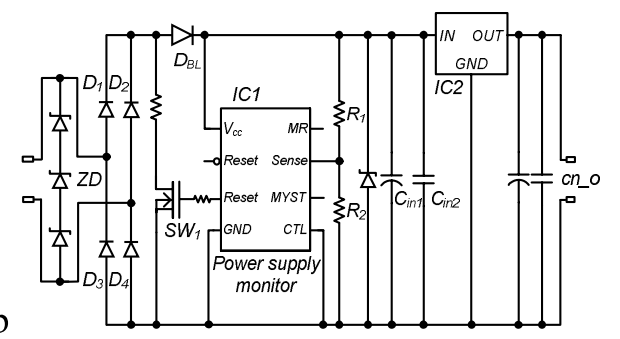

b

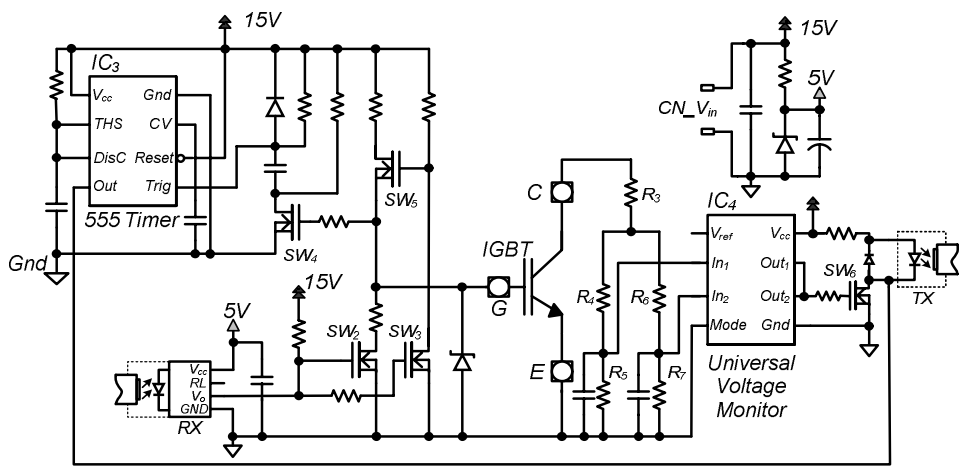

Fig. 2. (a) IGBT block with gate driver and gate power supply (b) proposed power supply utilizing energy in the system (c) gate driver circuit for IGBT having the function of voltage monitoring and status feedback 
is added. Fig. 2 (c) illustrates the IGBT gate driver. The voltage between collector and emitter, $V_{c e}$, of the IGBT is measured by using a universal voltage monitor, $I C_{4}$ whose input has a hysteresis band. Resistors forming voltage division circuit connected to the pin $\operatorname{In}_{1}$ or $\operatorname{In}_{2}$ of $I C_{4}, R_{3} \sim R_{7}$, determines voltage trip levels and values are selected to have $V_{c e}$ under $5500 \mathrm{~V}$ that is $85 \%$ voltage level of $6500 \mathrm{~V}$ IGBT used in this system. The IGBT is turned off by $S W_{2}$, and $S W_{5}$ are used for turning on. $S W_{6}$ and $S W_{5}$ have roles of generating a signal of status feedback when overvoltage occurs across the IGBT and triggering $I C_{3}$ for generating a short duration pulse corresponding to gate on-signal to make return signal via the fiber optic transmitter, TX, respectively.

\section{Driving scheme for bypass switch, thyristor}

A back-to-back connected thyristors and gate driver circuits and experimental results are shown in Fig. 3. As previously mentioned, the system has serially connected thyristor blocks. In cases where two thyristors have a common cathode connection, a single gate driver can be used to control both devices, so that the one gate signals for thyristor is connected to two thyristors having the same potential as shown in Fig. 3 (a).

Each thyristor gate driver has two ways of gating circuitry. One is electrically generated pulse circuits, and the other is a passive firing circuit providing low cost, highly reliable gating. The active pulse circuits are necessary for turning on all the thyristors instantaneously together after an input voltage sag event. A passive circuit consisting of relays, diodes and resistor provides an alternative firing mechanism for the thyristor in order to prepare for the situation of no power in the driver circuit or a malfunction of electrically generated pulse circuits. The relay used in this driving scheme has a normally closed contact, so that it remains in the closed state without a turn-off signal. Fig. 3 (a) shows the operational principle of passive gating. When load currents flow in the positive direction, left to right, the currents flowing via $D_{1} \rightarrow R_{12} \rightarrow R R_{12}$, and $D_{4} \rightarrow R_{34} \rightarrow R R_{34}$ paths provide the gate current of $\mathrm{TH}_{2}$ and $\mathrm{TH}_{3}$, respectively. A thyristor has a $P N P N$ structure and can be modeled as a combination of two transistors of $P N P\left(T_{1}\right)$ and $N P N\left(T_{2}\right)$. The anode current $I_{A}$ of a thyristor is related to gate current $I_{G}$ as [5]

$$
I_{A}=\frac{\alpha_{2} I_{G}+I_{C B o}}{1-\left(\alpha_{1}+\alpha_{2}\right)} .
$$

Where, and $\alpha_{1}$ and $\alpha_{2}$ are the common base current gain of $T_{1}$ and $T_{2}$, respectively. $I_{C B O}$ represents total leakage current of $T_{1}$ and $T_{2}$. By injecting gate current $I_{G}, \alpha_{1}+\alpha_{2}$ approaches 1 , and thyristors go into saturation or latching mode. When $I_{A}$ goes over the level of latching current of the device, the gate current does not have any control of the device. Since the gate current flows through the gate resistor $R_{12}$ and $R_{34}$ for positive load current before $I_{A}$ goes into saturation level, only a small power-rated resistor such as $10 \Omega / 10 \mathrm{~W}$ is used in this system. Fig. $3(\mathrm{~b})$ presents the input voltage waveform, gate signals of IGBT and thyristor, and thyristor current. At 
$t=t_{1}$, there occurs a sag event. Before $t_{1}$, thyristors remain on and the thyristor currents exist. After sag occurs, the IGBTs operate with PWM to regulate the output voltage. As the thyristors stop bypassing after $t_{1}$, thyristors do not carry the load currents.

Since a thyristor is a latching device, if thyristor current remains above the latching current level, there is no need of making gate signals for them. However, to monitor the condition of thyristor gate circuits and to simplify the thyristor control logic, a short gate pulse of $10 \mathrm{kHz}$ switching frequency is continuously applied to the gates in this scheme. The IGBTs operate with $1.5 \mathrm{kHz}$ switching frequency, where that of thyristor is $10 \mathrm{kHz}$, so that the gate signals of thyristor look denser than those of thyristor shown in Fig. 3 (b). Fig. 3 (c) shows the gate drivers circuits for thyristor and the relay, RR.

The relay having normally closed contact has to be turned off during PWM mode for removing the gate current path to the thyristor. Open command for the relay's contact is transferred by the $\mathrm{FET}_{3}$. The same power supply of Fig. 2 (b) is used for the gate power supply of the thyristors. The energy from the current transformer (CT) installed in the thyristor branch are used for the source of the power supply circuit. Since the output of the $\mathrm{CT}$ has a form of $\mathrm{AC}$, it is the reason why the diode bridge located in the input side of the power supply is necessary.

a

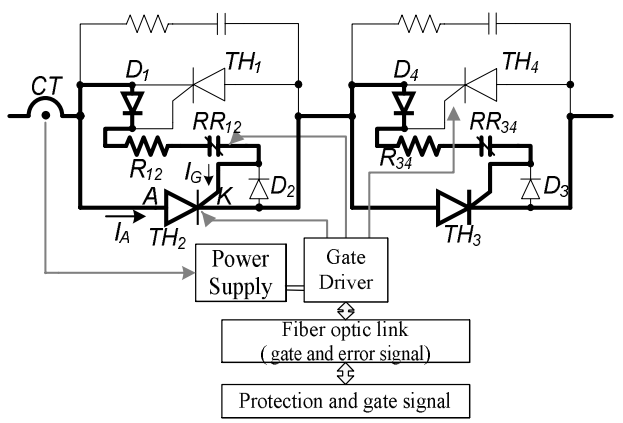

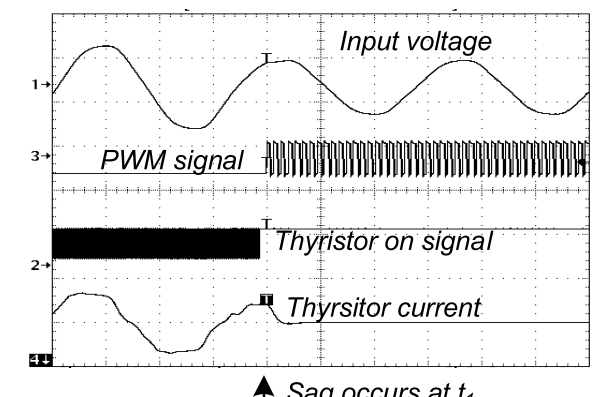

b

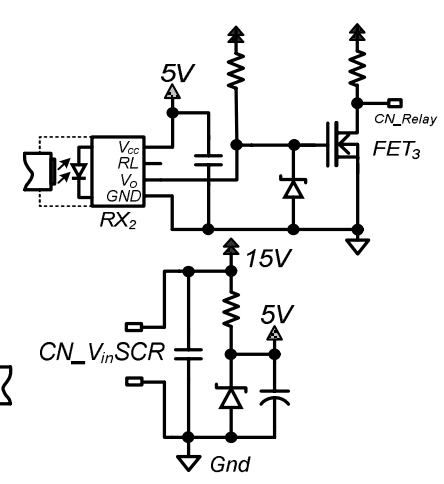

$\uparrow$ Sag occurs at $t_{1}$ c

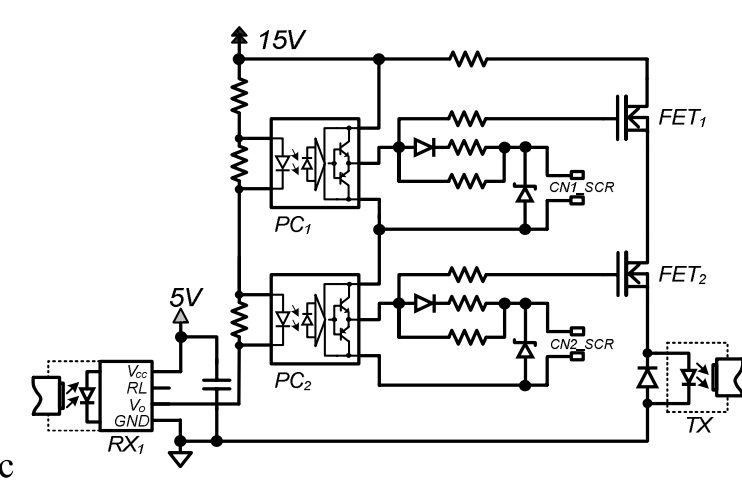

Fig. 3. (a) proposed gate driving scheme for thyristor and path shown for positive load current (b) experimental results of input voltage and thyristor current with gate signals (c) schematic of the gate driver for thyristors block 


\section{Conclusion}

A novel configuration of gate driving scheme with reliable gating circuitry for power switches and a floating power supply utilizing stored energy in the system has been proposed. The proposed gate driver has the function of fault detection and status feedback circuit. In addition, to eliminate the necessity of high voltage transformer for DC/DC converter, a new scheme of DC power supply has been devised. To increase the reliability of system, the gate circuit for thyristor has been developed to have two ways of operation with electrically pulsed circuits and passive firing circuit with relays. Experimental results implemented in a so-called voltage sag supporter have verified the validity of the proposed driving scheme.

\section{Acknowledgments}

This work was supported by the Hongik University new faculty research support fund. 